\title{
Seroprevalência de Anticorpos Contra o Sarampo em \\ Profissionais de Saúde de um Hospital Central em \\ Portugal
}

\section{Seroprevalence of Measles Antibodies in Healthcare Professionals in a Central Hospital in Portugal}

\author{
Gary NAVARRO MORALES ${ }^{1}$, Olena SHAPOVALOVA ${ }^{1}$, Ema SACADURA-LEITE ${ }^{1,2,3}$
}

Acta Med Port 2021 Feb;34(2):111-117 - https://doi.org/10.20344/amp.12907

\section{RESUMO}

Introdução: A imunidade contra o sarampo poderá resultar do contacto anterior com o vírus ou da vacinação. O objetivo deste estudo foi avaliar a prevalência de imunidade contra o sarampo em profissionais de saúde de um hospital central.

Material e Métodos: Estudo retrospetivo com caraterização dos resultados do doseamento de imunoglobulina G (IgG) específica contra o sarampo em profissionais de saúde, entre maio de 2010 e março de 2018.

Resultados: Analisaram-se os resultados de 1339 trabalhadores, média de idades $39,3 \pm 10,11$ anos, $71,1 \%$ mulheres. A prevalência de IgG positiva foi de $81,5 \%$, mais elevada entre os profissionais nas faixas etárias dos 40 aos 49 e mais de 50 anos $(91,9 \%$ e $94,6 \%$ respetivamente). Por sua vez, $83,1 \%$ dos profissionais com IgG negativa ou equívoca tinham maioritariamente idades inferiores a 40 anos $(p<0,05)$.

Discussão: Verificou-se que a prevalência de profissionais imunes ao sarampo foi mais baixa que noutros estudos, podendo, contudo, esse resultado dever-se a diferenças entre as caraterísticas das amostras estudadas. Foi encontrada uma maior suscetibilidade ao sarampo em profissionais nas faixas etárias inferiores. Estes resultados podem refletir uma baixa cobertura vacinal nesta faixa etária, um esquema de vacinação incompleto, ou a possibilidade dos profissionais mais velhos terem tido a doença, o que contribuíu para uma resposta imunitária com níveis de IgG mais elevados.

Conclusão: Conhecer a prevalência de profissionais suscetíveis ao sarampo, permitiu definir estratégias de prevenção face aos surtos que possam vir a acontecer. A vacinação continua a ser a melhor medida preventiva, uma terceira dose de vacina poderá vir a ser equacionada em determinados contextos epidemiológicos, especialmente nos profissionais expostos mais jovens.

Palavras-chave: Estudos Soroepidemiológicos; Portugal; Profissionais de Saúde; Sarampo/epidemiologia

\section{ABSTRACT}

Introduction: Immunity against measles may result from previous contact with the virus or vaccination. In this study we aimed to evaluate the prevalence of immunity to measles in healthcare professionals of a central hospital.

Material and Methods: Retrospective study, with description of the results of measles-specific IgG assay in healthcare professionals, between May 2010 and March 2018.

Results: The results of 1339 healthcare professionals were analyzed. The average age was $39.3 \pm 10.11$ years, $71.1 \%$ female. The prevalence of positive IgG was $81.5 \%$, higher among professionals in the age groups $40-49$ and over 50 years $(91.9 \%$ and $94.6 \%$ respectively). Healthcare professionals who presented negative or equivocal IgG were mostly under 40 years old $(83.1 \%)(p<0.05)$.

Discussion: The prevalence of serological immunity to measles in healthcare professionals was found to be lower than in other studies. That may be due to differences between the characteristics of the studied samples. Susceptibility to measles was higher in lower age groups. These results may reflect low vaccination coverage in this age group, an incomplete vaccination schedule, or the possibility of older healthcare professionals having the disease, which may confer an immune response with higher lgG levels.

Conclusion: Knowing the prevalence of susceptibility to measles in healthcare professionals enabled the establishment of prevention strategies for outbreaks that may occur. Vaccination remains the best preventative measure, but a third dose of vaccine may be considered in certain epidemiological contexts, particularly in the youngest exposed healthcare professionals.

Keywords: Health Personnel; Measles/epidemiology; Portugal; Seroepidemiologic Studies

\section{INTRODUÇÃO}

Os profissionais de saúde (PS), especialmente os não vacinados, parecem apresentar um maior risco de desenvolver sarampo, comparativamente à população geral em idade adulta, ${ }^{1-4}$ devido a uma maior probabilidade de exposição a casos de doença.

O sarampo é uma das doenças virais conhecidas mais contagiosas. ${ }^{5,6} \mathrm{O}$ vírus pertence ao género Morbillivirus, da família Paramixoviridae. É transmitido pessoa-a-pessoa,

por via aérea, através de aerossóis contendo gotículas de dimensões muito pequenas. As pessoas infetadas são geralmente contagiosas no período compreendido entre quatro dias antes até quatro dias após o início do exantema. ${ }^{5}$

O ser humano é o único hospedeiro natural do vírus, o que torna teoricamente viável a erradicação global da doença, uma vez que existe uma vacina eficaz e segura. ${ }^{5}$ A vacina apresenta taxas de seroconversão próximas de

1. Serviço de Saúde Ocupacional. Centro Hospitalar Universitário Lisboa Norte. Lisboa. Portugal.

2. Escola Nacional de Saúde Pública (ENSP/NOVA). Centro de Investigação em Saúde Pública (CISP/NOVA). Universidade NOVA de Lisboa. Lisboa. Portugal.

3. Instituto de Medicina Preventiva. Faculdade de Medicina. Universidade de Lisboa. Lisboa. Portugal.

$\square$ Autor correspondente: Gary Navarro Morales. garynavarro@gmail.com

Recebido: 04 de abril de 2019 - Aceite: 02 de setembro de 2020 - First published: 15 de dezembro de 2020 - Online issue published: 01 de fevereiro de 2021 Copyright $\odot$ Ordem dos Médicos 2021 
$95 \%{ }^{7}$ após uma única dose, e até $99 \%$ após duas doses. ${ }^{8}$ Contudo, e apesar da doença afetar mais frequentemente pessoas não vacinadas, também pode ocorrer em pessoas vacinadas. ${ }^{9-14}$

Muitos países têm feito progressos significativos no sentido de conseguir eliminar o sarampo. . $^{2,11,13,15}$ Os desafios enfrentados na Europa assumem particular importância face aos surtos recentes, que resultam maioritariamente de casos importados, associados à cobertura vacinal insuficiente entre subpopulações específicas (na Europa ainda existem variações significativas entre os países, em termos de políticas de vacinação e a sua implementação), ${ }^{3,14,15}$ e ao emergente movimento anti-vacinação. ${ }^{7,11,16}$

"Em Portugal a vacina monovalente contra o sarampo (VAS) foi incluída no Programa Nacional de Vacinação (PNV) em 1974. A vacina VASPR (vacina combinada contra sarampo, parotidite epidémica e rubéola) substituiu a VAS no PNV em 1987. Uma segunda dose da vacina VASPR, aos 11 - 13 anos de idade, foi introduzida no PNV em 1990, no sentido de ultrapassar as falências vacinais primárias (cerca de $5 \%$ dos vacinados). A segunda dose da vacina foi antecipada para os 5 - 6 anos de idade em 2000 (PNV 2000) e, em 2012, a idade de administração da primeira dose foi antecipada para os 12 meses". ${ }^{17}$

Segundo dados da Organização Mundial da Saúde relativos a 2018, em 47 dos 53 países da região europeia morreram 78 pessoas devido ao sarampo e cerca de 82 mil pessoas contraíram a doença. ${ }^{18} \mathrm{Em}$ Portugal foram confirmados 112 casos de sarampo em 2018. Destes casos, 99\% eram adultos, $13 \%$ não vacinados, $9 \%$ com esquema vacinal incompleto e $79 \%$ dos casos ocorreram em PS. ${ }^{19}$ Uma vez que a maioria dos PS estavam vacinados, e possivelmente por isso apresentaram quadros clínicos frustes ${ }^{6,20} \mathrm{e}$ possivelmente menos contagiosos, ${ }^{3,13}$ poder-se-á questionar se aspetos relacionados com o tempo decorrido entre a última dose da vacinação e a exposição que poderão ter influenciado a manutenção da resposta imunitária (apesar de se tratar de uma vacina viva atenuada e, portanto, associada a respostas imunitárias mais intensas e duradouras).

Segundo o Inquérito Serológico Nacional 2016-2017 realizado pelo Instituto Nacional de Saúde Doutor Ricardo Jorge encontrou-se, na população geral, uma prevalência de imunoglobulina $\mathrm{G}$ ( $\mathrm{lgG}$ ) positiva contra o sarampo de $94,2 \%$ e negativa de $5,8 \%$. A percentagem de indivíduos seropositivos (com lgG positiva) foi superior a $95 \%$ nas crianças entre os dois e os nove anos e nos indivíduos com idade superior a 44 anos. Nos restantes grupos etários a distribuição dos casos seropositivos variou entre os $77,9 \%$ (20 - 29 anos) e os 91,0\% (30 - 44 anos). ${ }^{21}$

Alguns trabalhos sobre a imunidade contra o sarampo em profissionais de saúde identificaram uma suscetibilidade à doença que variou entre $3,3 \%$ e $16 \% .^{1,22-26}$

No entanto, a suscetibilidade dos PS depende de fatores como a epidemiologia da doença no país em estudo, a data da realização desse mesmo estudo, a idade dos PS e a sua cobertura vacinal, entre outros fatores.

Os autores não têm conhecimento de quaisquer dados publicados acerca da prevalência de seroconversão contra o sarampo em PS portugueses. A imunidade contra o sarampo, evidenciada pela presença de IgG específica positiva, poderá resultar do contacto anterior com o vírus (com ou sem registo de doença pregressa) ou da vacinação. $O$ objetivo deste estudo foi avaliar a prevalência de imunidade contra o sarampo, objetivada pelo resultado positivo da IgG específica numa amostra de profissionais de saúde de um hospital universitário português, e explorar alguns fatores que se possam associar a resultados de $\lg G$ negativa e equívoca.

\section{MATERIAL E MÉTODOS}

Desenho do estudo: estudo observacional e transversal, com análise retrospetiva de processos clínicos, descritivo, mas incluindo uma componente analítica.

A amostra em estudo foi constituída pelos PS observados no serviço de Saúde Ocupacional (SSO) de um hospital central e universitário, no âmbito de exames de Medicina do Trabalho. Selecionaram-se os PS que realizaram doseamento de IgG contra o sarampo entre maio de 2010 e março de 2018, por não existir registo vacinal ou história de ter tido a doença.

A análise retrospetiva dos processos clínicos dos profissionais em estudo foi realizada no último semestre de 2018 para caraterização de dados sociodemográficos, profissionais e resultados de testes serológicos contra o sarampo. Foi ainda efetuado o levantamento do histórico vacinal do grupo de PS que tinham apresentado lgG negativa e IgG equívoca e a que, posteriormente à determinação serológica, nos foi possível aceder.

A determinação de anticorpos do tipo lgG contra o sarampo foi realizada pelo Serviço de Patologia Clínica do Hospital em estudo utilizando o método ELFA (enzyme-linked fluorescent assay), variante do enzyme-linked immunosorbent assay (ELISA). O cut-off do índice (referido pelo laboratório) para o resultado negativo foi de $<0,5$, para o equívoco foi entre $0,5-0,7$ e para o positivo se $>$ ou $=$ 0,7 .

A análise estatística foi realizada com recurso ao programa estatístico IBM Statistical Package for the Social Sciences $\left(S P S S^{\circledR}\right)$, versão 25 . Procedeu-se à análise descritiva para a caracterização da amostra, segundo o resultado serológico da lgG específica contra o sarampo. Para o estudo de associações entre variáveis foi utilizado o teste do qui-quadrado, tendo-se considerado um nível de significância de cinco por cento.

Os procedimentos seguidos estiveram de acordo com regulamentos estabelecidos pelos responsáveis da Comissão de Ética do Hospital, e de acordo com a Declaração de Helsínquia da Associação Médica Mundial.

\section{RESULTADOS}

Durante o período em estudo, um total de 1339 trabaIhadores realizaram doseamento da IgG contra o sarampo. A média de idades da amostra foi de 39,3 $\pm 10,11$ anos (mediana 38; min 19 - máx 65 ) e 71,1\% eram do sexo feminino. 
Tabela 1 - Seroprevalência da lgG contra o sarampo segundo as características sociodemográficas e profissionais da amostra estudada

\begin{tabular}{|c|c|c|c|c|c|}
\hline Resultado IgG sarampo & $\begin{array}{c}\text { Positivo } \\
\text { n (\%) }\end{array}$ & $\begin{array}{c}\text { Equívoco } \\
\mathrm{n}(\%)\end{array}$ & $\begin{array}{c}\text { Negativo } \\
\mathrm{n}(\%)\end{array}$ & $\begin{array}{l}\text { Total } \\
\mathrm{n}(\%)\end{array}$ & $p$ \\
\hline \multicolumn{6}{|l|}{ Sexo } \\
\hline Homem & $306(79,1)$ & $31(8,0)$ & $50(12,9)$ & $387(100)$ & \multirow{3}{*}{0,315} \\
\hline Mulher & $785(82,5)$ & $59(6,2)$ & $108(11,3)$ & $952(100)$ & \\
\hline$H+M$ & $1091(81,5)$ & $90(6,7)$ & $158(11,8)$ & $1339(100)$ & \\
\hline \multicolumn{6}{|l|}{ Faixa etária } \\
\hline$<30$ & $158(62,9)$ & $31(12,4)$ & $62(24,7)$ & $251(100)$ & \multirow{4}{*}{0,000} \\
\hline $30-39$ & $367(76,5)$ & $39(8,1)$ & $74(15,4)$ & $480(100)$ & \\
\hline $40-49$ & $319(91,9)$ & $13(3,7)$ & $15(4,3)$ & $347(100)$ & \\
\hline$\geq 50$ & $247(94,6)$ & $7(2,7)$ & $7(2,7)$ & $261(100)$ & \\
\hline \multicolumn{6}{|l|}{ Categoria profissional } \\
\hline Pessoal de enfermagem & $362(81,5)$ & $28(6,3)$ & $54(12,2)$ & $444(100)$ & \multirow{6}{*}{0,442} \\
\hline Assistente operacional & $307(83,9)$ & $25(6,8)$ & $34(9,3)$ & $366(100)$ & \\
\hline Pessoal médico & $208(77,9)$ & $24(9,0)$ & $35(13,1)$ & $267(100)$ & \\
\hline Técnico de diagnóstico e terapêutica & $96(85,7)$ & $4(3,6)$ & $12(10,7)$ & $112(100)$ & \\
\hline Assistente técnico & $69(81,2)$ & $4(4,7)$ & $12(14,1)$ & $85(100)$ & \\
\hline Outros & $49(75,4)$ & $5(7,7)$ & $11(16,9)$ & $65(100)$ & \\
\hline
\end{tabular}

O pessoal de enfermagem e os assistentes operacionais foram os grupos profissionais com maior representatividade na amostra.

Em dezembro de 2018, o Hospital em estudo contava com 6281 colaboradores, distribuídos pelos seguintes grupos profissionais: 48 dirigentes, 1442 médicos, 1940 enfermeiros, 255 técnicos superiores de saúde e outros técnicos superiores, 494 técnicos de diagnóstico e terapêutica, 601 assistentes técnicos, 1472 assistentes operacionais, e 29 profissionais não diretamente ligados à saúde, mas essenciais ao funcionamento hospitalar como advogados ou engenheiros informáticos.

Não havia registos documentados de patologias habitualmente associadas a imunossupressão, doenças autoimunes ou PS que tivessem efetuado medicação em doses imunossupressoras nos processos clínicos dos PS que constituíram a amostra em estudo.

\section{Distribuição dos resultados serológicos da IgG especí- fica na amostra em estudo}

Dos 1339 trabalhadores, 81,5\% $(n=1091)$ tinham IgG positiva, 6,7\% ( $n=90) \lg$ equívoca e $11,8 \%(n=158) \lg G$ negativa (Tabela 1 ).

Não se verificou diferença significativa nos resultados serológicos entre sexos. Os PS nas faixas etárias dos 40 - 49 e com mais de 50 anos tiveram prevalências de imunidade contra o sarampo ( $\lg$ específica contra o sarampo positiva) mais elevadas, $91,9 \%$ e $94,6 \%$ respetivamente. Por sua vez, os PS com idades entre os 19 - 29 anos foram os que apresentaram menores proporções de indivíduos com IgG positiva (62,9\%). Os PS com IgG negativa ou equívoca tinham maioritariamente idades inferiores a 40 anos (83,1\%). A diferença dos resultados serológicos entre faixas etárias foi estatisticamente significativa $(p=0,000)$.
O grupo constituído por 'outros PS' e o do 'pessoal médico' foram os grupos profissionais com maiores proporções de IgG negativa ou equívoca, $24,6 \%$ e $22,1 \%$ respetivamente. Contudo, nestes grupos predominavam indivíduos mais jovens (11/16 dos 'outros PS' tinham entre 30 - 39 anos; $32 / 59$ do 'pessoal médico' tinha menos de 30 anos e 23/59 entre 30 - 39 anos). Apesar disso, a diferença encontrada entre grupos profissionais não foi estatisticamente significativa.

\section{Caraterização vacinal dos PS com resultado de IgG equívoco}

Dos 90 profissionais com resultado de $\lg G$ equívoco, $41,1 \%(n=37)$ tinham registo de duas doses de vacina e $24,4 \%(n=22)$ de uma dose (Tabela 2$)$.

Quando verificada a data de administração da última dose da vacina (VAS/VASPR) nos 59 profissionais com histórico vacinal, encontrou-se que quase metade $(42,4 \%$; $n=$ 25) tinham-na efetuado há 11 - 20 anos (mediana 15 anos) (Tabela 3). Tendo em consideração a idade dos PS verificou-se que $84 \%$ dos PS com idade inferior a 30 anos e com $\lg$ equívoca tinham feito a última dose 11 - 20 anos antes, e $42,9 \%$ dos $P S$ com IgG equívoca na faixa etária entre 30 - 39 anos tinham-na feito 21 - 30 anos antes (Tabela 4).

\section{Caraterização vacinal dos PS com resultado de IgG ne- gativo}

Dos 158 profissionais com IgG negativo, 51,9\% ( $n=82)$ tinham esquema de vacinação completo e $22,2 \%(n=35)$ tinham feito uma dose de vacina (esquema de vacinação incompleto) (Tabela 2).

Nos 117 profissionais com IgG negativa que tinham histórico de terem feito pelo menos uma dose da vacina verificou-se que a última dose tinha sido administrada em 
Tabela 2 - Caracterização vacinal dos PS com resultado de IgG equívoco e negativo

\begin{tabular}{|c|c|c|c|c|c|}
\hline \multirow{2}{*}{\multicolumn{2}{|c|}{ Resultado IgG }} & \multicolumn{4}{|c|}{ Esquema vacinal } \\
\hline & & \multirow{2}{*}{$\begin{array}{c}\text { Incompleto } \\
22\end{array}$} & \multirow{2}{*}{$\begin{array}{c}\text { Completo } \\
37\end{array}$} & \multirow{2}{*}{$\begin{array}{c}\text { Desconhecido } \\
31\end{array}$} & \multirow{2}{*}{$\begin{array}{c}\text { Total } \\
90\end{array}$} \\
\hline Equívoc & $\mathrm{n}$ & & & & \\
\hline Equivoco & $\%$ & $24,40 \%$ & $41,10 \%$ & $34,40 \%$ & $100 \%$ \\
\hline \multirow{2}{*}{ Negativo } & $\mathrm{n}$ & 35 & 82 & 41 & 158 \\
\hline & $\%$ & $22,20 \%$ & $51,90 \%$ & $25,90 \%$ & $100 \%$ \\
\hline \multirow{2}{*}{ Total } & $\mathrm{n}$ & 57 & 119 & 72 & 248 \\
\hline & $\%$ & $23,00 \%$ & $48,00 \%$ & $29,00 \%$ & $100 \%$ \\
\hline
\end{tabular}

mais de metade $(55,6 \% ; n=55)$ há $11-20$ anos (mediana 15 anos) (Tabela 3). Considerando-se também a idade dos PS, verificou-se que $84,2 \%$ dos PS com idade $<30$ anos e com IgG negativa tinham feito a última dose 11 - 20 anos atrás. Os PS com idade entre os 30 - 39 anos que apresentaram IgG negativa à data da última dose da vacina tinha maior variação relativamente ao tempo decorrido desde a última dose da vacina (entre os 11 e os 39 anos antes do doseamento) (Tabela 4).

\section{DISCUSSÃO}

A prevalência de PS com imunidade contra o sarampo evidenciada por IgG positiva foi de $81,5 \%$. Os nossos resultados encontraram uma menor prevalência de IgG positiva no grupo de PS com idade inferior a 30 anos comparativamente aos resultados do último inquérito serológico nacional em 2016 - 2017 (62,9\% vs 77,9\%). Em Portugal, já passaram quase 45 anos desde o início da vacinação organizada contra o sarampo. "As coberturas vacinais da VASPR (uma ou duas doses), a nível nacional, são superiores a $95 \%$ pelo menos desde 2006 . Este valor não é uniforme, e têm-se verificado assimetrias regionais e locais que aumentam o risco de existência de bolsas de população suscetível, mesmo em áreas geográficas com cobertura vacinal global elevadas". ${ }^{17}$ A realização dos testes em laboratórios ${ }^{27}$ e em tempos diferentes poderá ter contribuído para as diferenças encontradas, assim como taxas de vaci- nação distintas ou ainda a proporção de indivíduos que encontrámos com IgG equívoca. De facto, se incluirmos como tendo imunidade os PS com IgG específica contra o sarampo classificada como equívoca, a prevalência encontrada aumenta para $88,2 \%$. Na verdade, o significado desse resultado serológico é incerto, mas permite-nos supor que o antigénio não é de todo desconhecido para o organismo, podendo eventualmente indicar que os anticorpos séricos possam ter diminuído ao longo do tempo após a resposta imunitária inicial, mas cuja memória imunológica se poderá manter. Sendo assim, perante um novo contacto com o antigénio, uma resposta secundária seria passível de vir a ser desencadeada.

No nosso estudo, a suscetibilidade ao sarampo está acima da maioria dos resultados publicados para os $\mathrm{PS}^{22-}$ 25,28-30 (a metodologia mais utilizada nos outros estudos foi semelhante à utilizada no nosso). Num estudo realizado na Catalunha encontrou-se suscetibilidade ao sarampo de $6 \%{ }^{25}$ Noutro estudo no Reino Unido, a suscetibilidade ao sarampo foi de $3,3 \%{ }^{23}$ e num estudo na Itália de $16 \% .{ }^{26}$ Nos Estados Unidos da América, a suscetibilidade foi de $4 \%{ }^{1} \mathrm{e}$ no Japão de $8,2 \% .^{24}$

No entanto, os nossos resultados podem refletir o facto de ter sido usada uma amostra de conveniência, o que aliás constitui uma limitação deste estudo. A análise serológica foi apenas realizada aos PS cujo registo vacinal era desconhecido à data do exame médico, não tendo sido

Tabela 3 - Intervalo de anos decorridos entre a vacinação e o doseamento da IgG nos PS com resultado equívoco e negativo

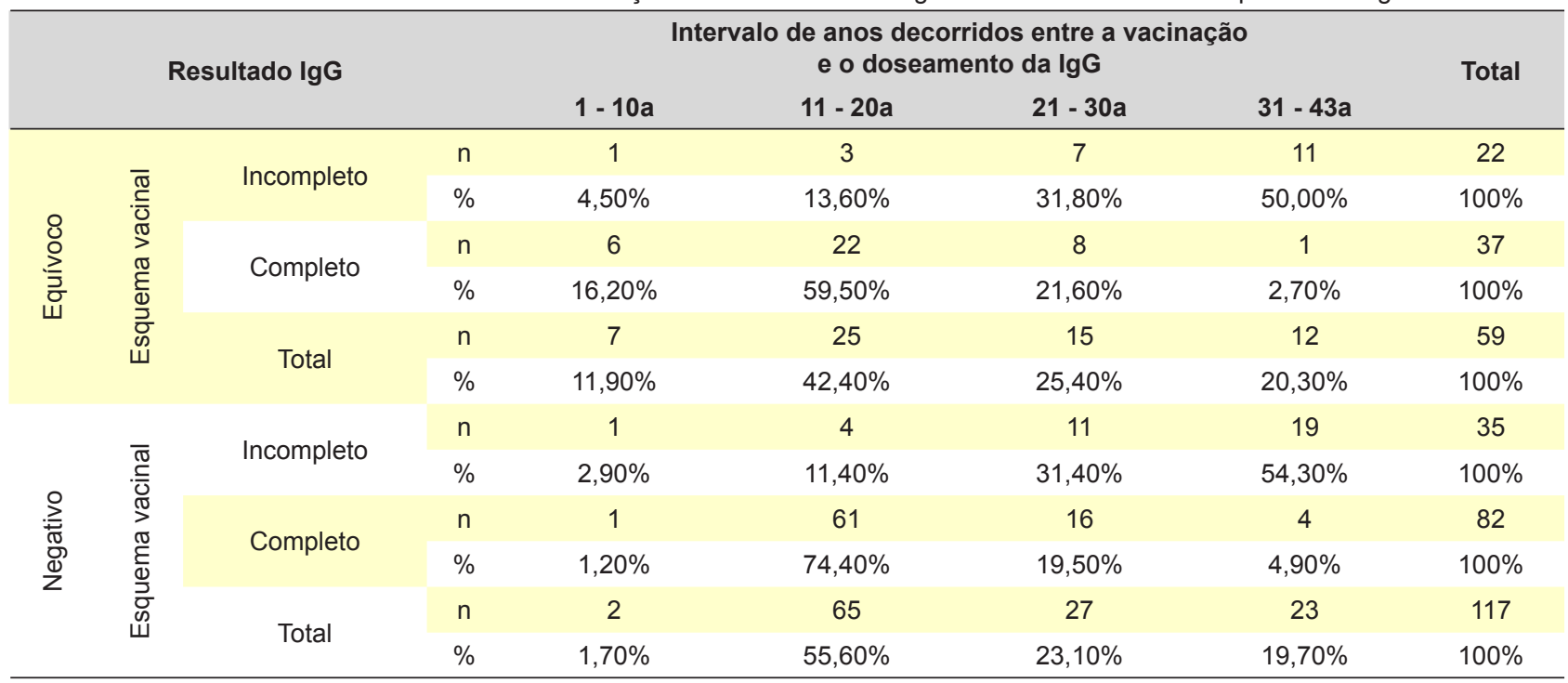


Tabela 4 - Intervalo de anos decorridos entre a vacinação e o doseamento da IgG segundo a faixa etária nos PS com resultado equívoco e negativo

\begin{tabular}{|c|c|c|c|c|c|c|c|c|}
\hline & \multicolumn{3}{|c|}{ Resultado IgG } & \multicolumn{4}{|c|}{$\begin{array}{c}\text { Intervalo de anos decorridos entre a vacinação } \\
\text { e o doseamento da IgG }\end{array}$} & \multirow[t]{2}{*}{ Tota } \\
\hline & & & & $1-10 a$ & $11-20 a$ & $21-30 a$ & $31-43 a$ & \\
\hline \multirow{10}{*}{ 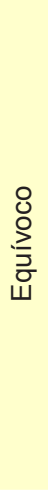 } & \multirow{10}{*}{ 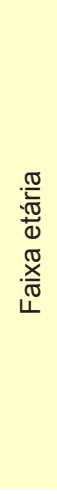 } & \multirow{2}{*}{$<30 a$} & $\mathrm{n}$ & 1 & 21 & 3 & 0 & 25 \\
\hline & & & $\%$ & $4,00 \%$ & $84,00 \%$ & $12,00 \%$ & $0,00 \%$ & $100 \%$ \\
\hline & & \multirow{2}{*}{$30-39 a$} & $\mathrm{n}$ & 5 & 4 & 12 & 7 & 28 \\
\hline & & & $\%$ & $17,90 \%$ & $14,30 \%$ & $42,90 \%$ & $25,00 \%$ & $100 \%$ \\
\hline & & \multirow{2}{*}{$40-49 a$} & $n$ & 0 & 0 & 0 & 5 & 5 \\
\hline & & & $\%$ & $0,00 \%$ & $0,00 \%$ & $0,00 \%$ & $100,00 \%$ & $100 \%$ \\
\hline & & \multirow{2}{*}{$>50 a$} & $n$ & 1 & 0 & 0 & 0 & 1 \\
\hline & & & $\%$ & $100,00 \%$ & $0,00 \%$ & $0,00 \%$ & $0,00 \%$ & $100 \%$ \\
\hline & & \multirow{2}{*}{ Total } & $\mathrm{n}$ & 7 & 25 & 15 & 12 & 59 \\
\hline & & & $\%$ & $11,90 \%$ & $42,40 \%$ & $25,40 \%$ & $20,30 \%$ & $100 \%$ \\
\hline \multirow{8}{*}{ 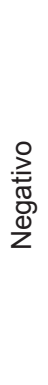 } & \multirow{8}{*}{ 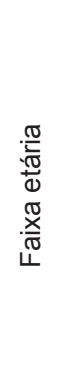 } & \multirow{2}{*}{$<30 a$} & $n$ & 1 & 48 & 8 & 0 & 57 \\
\hline & & & $\%$ & $1,80 \%$ & $84,20 \%$ & $14,00 \%$ & $0,00 \%$ & $100 \%$ \\
\hline & & \multirow{2}{*}{$30-39 a$} & $\mathrm{n}$ & 0 & 16 & 19 & 20 & 55 \\
\hline & & & $\%$ & $0,00 \%$ & $29,10 \%$ & $34,50 \%$ & $36,40 \%$ & $100 \%$ \\
\hline & & \multirow{2}{*}{$40-49 a$} & $\mathrm{n}$ & 1 & 1 & 0 & 3 & 5 \\
\hline & & & $\%$ & $20,00 \%$ & $20,00 \%$ & $0,00 \%$ & $60,00 \%$ & $100 \%$ \\
\hline & & \multirow{2}{*}{ Total } & $\mathrm{n}$ & 2 & 65 & 27 & 23 & 117 \\
\hline & & & $\%$ & $1,70 \%$ & $55,60 \%$ & $23,10 \%$ & $19,70 \%$ & $100 \%$ \\
\hline
\end{tabular}

solicitada a serologia aos PS que evidenciaram registo de duas doses de VAS/VASPR (assumiu-se imunidade presuntiva) 6 ou uma dose de VAS/VASPR (nestes últimos completou-se o esquema de duas doses). Assim, a prevalência de PS com lgG positiva seria provavelmente maior, pois incluiria todos os PS, independentemente da presença de registos na data do exame de saúde. Por outro lado, verificámos que a amostra do nosso estudo era relativamente jovem (mediana de 38 anos), o que também poderá ter contribuído para a menor prevalência de lgG positiva encontrada. ${ }^{30}$

No surto de sarampo em Portugal em 2018, $79 \%$ dos 112 casos confirmados ocorreram em PS. Do total dos casos, apenas $13 \%$ não estavam vacinados e $9 \%$ tinham esquema de vacinação incompleto. ${ }^{19}$ Verificámos ainda que uma percentagem elevada de PS com IgG negativa tinha efetuado uma ou duas doses de vacinação. Dos PS com IgG negativa ou equívoca ( $n=248)$, quase metade $(48 \%)$ tinha esquema de vacinação completo e $23 \%$ tinha efetuado uma dose de vacina. Considerando apenas os PS com IgG negativa, constatou-se que $51,9 \%$ tinham efetuado duas doses da vacina e apenas 25,9\% (41 PS) não tinham registo de vacinação contra o sarampo. Estes resultados levam-nos a equacionar a possibilidade de, em presenca de surtos, poder ser administrada uma terceira dose da vacina contra o sarampo para PS expostos.

No nosso estudo, a suscetibilidade ao sarampo, avaliada pela IgG específica contra o sarampo, revelou ser superior nos PS mais jovens (faixa etária inferior a 30 anos), o que também tem sido encontrado noutros estudos. ${ }^{22-26}$
Estes resultados podem refletir uma baixa cobertura vacinal nesta faixa etária ou um esquema de vacinação incompleto, ${ }^{4,15}$ mas também o facto dos mais velhos terem tido contacto com a doença, o que Ihes conferiu uma resposta imunitária mais robusta.

Os nossos resultados não permitem sugerir que o tempo decorrido entre a última dose da vacina e a presença de seroprevalência de $\lg G$ negativa ou equívoca possam estar associados. De facto, confirmámos que os PS com IgG negativa e pelo menos uma dose de vacina, haviam-na realizado maioritariamente há 11 - 20 anos, mais frequentemente em indivíduos com menos de 30 anos. O tipo e caraterísticas da nossa amostra e o desenho do estudo podem ter sido pelo menos parcialmente responsáveis pelos resultados encontrados, pelo que se sugere a realização de estudos longitudinais e com amostras aleatórias para poder concluir sobre a influência desta variável nos resultados serológicos. ${ }^{7,30}$

\section{CONCLUSÃO}

A prevalência de lgG positiva foi de $81,5 \%$, tendo sido mais elevada entre os PS nas faixas etárias dos 40 - 49 e idade superior a 50 anos (91,9\% e 94,6\% respetivamente). Por sua vez, $83,1 \%$ dos profissionais que apresentaram IgG negativa ou equívoca tinham maioritariamente idades inferiores a 40 anos $(p<0,05)$. Conhecer a prevalência de PS suscetíveis ao sarampo no nosso centro hospitalar permitiu definir estratégias de prevenção ${ }^{3,20,26,30,31}$ face aos surtos que possam acontecer nos anos seguintes, designadamente, verificar sistematicamente o status de 
imunização/imunidade dos PS admitidos, vacinar aqueles que precisam, formar e informar os PS do risco individual e desenvolver orientações internas perante exposições não protegidas a doentes com sarampo. A vacinação continua a ser a melhor medida preventiva, ${ }^{2,3,7,16,20,26,31}$ não só no âmbito da prevenção da transmissão nosocomial da doença, como também no contributo à erradicação/eliminação do sarampo. Contudo, uma terceira dose $\mathrm{e}^{15}$ de vacina poderá vir a ser equacionada em determinados contextos epidemiológicos, mais especificamente na presença de surtos em profissionais de saúde mais jovens.

\section{PROTEÇÃO DE PESSOAS E ANIMAIS}

Os autores declaram que os procedimentos seguidos estavam de acordo com os regulamentos estabelecidos pelos responsáveis da Comissão de Investigação Clínica e Ética e de acordo com a Declaração de Helsínquia da Associação Médica Mundial atualizada em 2013.

\section{CONFIDENCIALIDADE DOS DADOS}

Os autores declaram ter seguido os protocolos do seu centro de trabalho acerca da publicação de dados.

\section{CONFLITOS DE INTERESSE}

Os autores declaram não ter conflitos de interesses relacionados com o presente trabalho.

\section{FONTES DE FINANCIAMENTO}

Este trabalho não recebeu qualquer tipo de suporte financeiro de nenhuma entidade no domínio público ou privado.

\section{REFERÊNCIAS}

1. Steingart KR, Thomas AR, Dykewicz CA, Redd SC. Transmission of measles virus in healthcare settings during a communitywide outbreak. Infect Control Hosp Epidemiol. 1999;20:115-9.

2. Maltezou H, Dedoukou X, Pavi E, Theodoridou M, Athanasakis K. Costs associated with measles in healthcare personnel during the 2017-2018 epidemic in Greece: a real-world data cost-of-illness analysis. J Hosp Infect. 2020;105:91-4.

3. Hiller U, Mankertz A, Köneke N, Wicker S. Hospital outbreak of measles - evaluation and costs of 10 occupational cases among healthcare worker in Germany, February to March 2017. Vaccine. 2019;37:1905-9.

4. Ödemiş Í, Köse Ş, Akbulut Í, Albayrak H. Seroprevalence of measles, mumps, rubella, and varicella zoster virus antibodies among healthcare students: analysis of vaccine efficacy and cost-effectiveness. Rev Esp Quimioter. 2019;32:525-31.

5. European Centre for Disease Prevention and Control. Factsheet about measles. Infectious diseases and public health. [consultado 2020 maio 31]. Disponível em: https://www.ecdc.europa.eu/en/measles/facts/ factsheet. Published 2016.

6. Park J, Yu S, Park E, Lee Y, Park S, Jeon M. Modified measles in an anti-measles immunoglobulin G-negative healthcare worker who had received two doses of measles-containing vaccine. Infect Chemother. 2019;51:305.

7. Di Pietrantonj C, Rivetti A, Marchione P, Debalini M, Demicheli V. Vaccines for measles, mumps, rubella, and varicella in children. Cochrane Database Syst Rev. 2020;4:CD004407.

8. Centers for Disease Control and Prevention. Epidemiology and prevention of vaccine-preventable disease. Hamborsky J, Kroger A, Wolfe S, editors. 13 $3^{\text {th }}$ ed. Washington: Public Health Foundation; 2015.

9. Centers for Disease Control and Prevention. Measles - United States, January 1 - May 23, 2014. Morbidity and mortality weekly report (MMWR). [consultado 2019 jun 27]. Disponível em: https://www.cdc. gov/mmwr/preview/mmwrhtml/mm6322a4.htm.

10. Centers for Disease Control and Prevention. Measles - United States, January 1 - August 24, 2013. Morbidity and mortality weekly report (MMWR). [consultado 2019 jun 27]. Disponível em: https://www.cdc. $\mathrm{gov} / \mathrm{mmwr} / \mathrm{preview} / \mathrm{mmwrhtml} / \mathrm{mm} 6236 \mathrm{a} 2 . \mathrm{htm}$.

11. Sowers S, Rota J, Hickman C, Mercader S, Redd S, McNall R, et al High concentrations of measles neutralizing antibodies and high-avidity measles IgG accurately identify measles reinfection cases. Clin Vaccine Immunol. 2016;23:707-16.

12. Loulerque P, Guthmann JP, Fonteneau L, Armengaud JB, Levy-Brühl D, Launay O. Susceptibility of health care students to measles, Paris, France. Emerg Infect Dis. 2011;17:1766-7.

13. Rosen J, Rota J, Hickman C, Sowers S, Mercader S, Rota P, et al. Outbreak of measles among persons with prior evidence of immunity, New York City, 2011. Clin Infect Dis. 2014;58:1205-10.

14. European Centre for Disease Prevention and Control. Measles. Annual epidemiological report for 2019. 2020. [consultado 2020 maio 31]. Disponível em: https://www.ecdc.europa.eu/sites/default/files/ documents/measles-2019-aer.pdf.
15. Maltezou H, Botelho-Nevers E, Brantsæter A, Carlsson R, Heininger $\mathrm{U}$, Hübschen $\mathrm{J}$, et al. Vaccination of healthcare personnel in Europe: update to current policies. Vaccine. 2019;37:7576-84.

16. Maltezou $\mathrm{H}$, Wicker $\mathrm{S}$. Measles in health-care settings. Am J Infect Control. 2013;41:661-3.

17. Leça A, Freitas M, Fernandes T. Programa Nacional de Eliminação do Sarampo. Norma da Direção-Geral da Saúde. Lisboa: DGS; 2013.

18. World Health Organization. Measles in Europe: record number of both sick and immunized. Online. [consultado 2019 jul 03]. Disponível em: http://www.euro.who.int/en/media-centre/sections/press-releases/2019/ measles-in-europe-record-number-of-both-sick-and-immunized.

19. Direção-Geral da Saúde, Instituto Nacional de Saúde Dr. Ricardo Jorge. Boletim epidemiológico: Sarampo em Portugal - Situação a 28 de maio de 2018. 2018. [consultado 2019 jun 27]. Disponível em: https:// www.dgs.pt/paginas-de-sistema/saude-de-a-a-z/sarampo1/boletimepidemiologico.aspx.

20. Cheng V, Wong SC, Wong S, Sridhar S, Chen J, Yip C, et al. Measles outbreak from Hong Kong International Airport to the hospital due to secondary vaccine failure in healthcare workers. Infect Control Hosp Epidemiol. 2019;40:1407-15.

21. Instituto Nacional de Saúde Doutor Ricardo Jorge. Inquérito Serológico Nacional 2015-2016: Doenças evitáveis por vacinação. [consultado 2019 jul 4]. Disponível em: https://repositorio.insa.pt/ bitstream/10400.18/5401/1/INSA_ISN-2015-2016-DEV_web.pdf. Published 2017.

22. Uckay I, Hugonnet S, Kaiser L, Sax H, Pittet D. Age limit does not replace serologic testing for determination of immune status for measles. Infect Control Hosp Epidemiol. 2007;28:1117-20.

23. Ziegler E, Roth C, Wreghitt T. Prevalence of measles susceptibility among health care workers in a UK hospital. Does the UK need to introduce a measles policy for its health care workers? Occup Med. 2003;53:398-402.

24. Kumakura S, Shibata H, Onoda K, Nishimura N, Matsuda C, Hirose M. Seroprevalence survey on measles, mumps, rubella and varicella antibodies in healthcare workers in Japan: Sex, age, occupationalrelated differences and vaccine efficacy. Epidemiol Infect. 2014;142:129.

25. Fernández-Cano $M$, Armadans $L$, Sulleiro $E$, Espuga $M$, Ferrer $E$, Martínez-Gómez X, et al. Susceptibilidad frente a sarampión y varicela en el personal sanitario de un hospital de tercer nivel en Cataluña. Enferm Infecc Microbiol Clin. 2012;30:184-8.

26. Ledda C, Cinà D, Garozzo S, Vella F, Consoli A, Scialfa V, et al. Vaccine-preventable disease in healthcare workers in Sicily (Italy): seroprevalence against measles. Future Microbiol. 2019;14:S33-6.

27. Jo SY, Shin K, Lee S, Jeong E, Lee H, Chang C. Comparison of three immunoassays for determination of immunity to rubella virus in healthcare workers. J Immunol Methods. 2018;463:84-8.

28. Urbiztondo L, Borràs $\mathrm{E}$, Costa J, Broner S, Campins M, Bayas J, et al. Prevalence of measles antibodies among health care workers in Catalonia (Spain) in the elimination era. BMC Infect Dis. 2013;13:391. 
29. Seo S, Malak S, Lim S, Eagan J, Sepkowitz K. Prevalence of measles antibody among young adult healthcare workers in a cancer hospital: 1980s versus 1998-1999. Infect Control Hosp Epidemiol. 2002;23:2768.

30. Kim SK, Jung J, Kwak S, Hong M, Kim SH. Seroprevalence of mumps in healthcare workers in South Korea. Clin Exp Vaccine Res. 2020;9:64

31. Orsi A, Butera F, Piazza M, Schenone S, Canepa P, Caligiuri $P$, et al.

Analysis of a 3-months measles outbreak in western Liguria, Italy: are hospital safe and healthcare workers reliable? J Infect Public Health. 2020;13:619-24. 